\title{
Effect of Treatment of Sprague Dawley Rats with AVE7688, Enalapril, or Candoxatril on Diet-Induced Obesity
}

\author{
Eric P. Davidson,, ${ }^{1,2}$ Lawrence J. Coppey, ${ }^{1,2}$ Brian Dake, ${ }^{1,2}$ and Mark A. Yorek ${ }^{1,2}$ \\ ${ }^{1}$ Veteran Affairs Medical Center, Iowa City, IA 52246, USA \\ ${ }^{2}$ Department of Internal Medicine, The University of Iowa, Iowa City, IA 52242, USA
}

Correspondence should be addressed to Mark A. Yorek, mark-yorek@uiowa.edu

Received 21 April 2010; Accepted 29 June 2010

Academic Editor: A. Halpern

Copyright (C) 2011 Eric P. Davidson et al. This is an open access article distributed under the Creative Commons Attribution License, which permits unrestricted use, distribution, and reproduction in any medium, provided the original work is properly cited.

\begin{abstract}
The objective of this study was to determine the effect of AVE7688, a drug that inhibits both angiotensin converting enzyme (ACE) and neutral endopeptidase (NEP) activity, on neural and vascular defects caused by diet induced obesity (DIO). Rats at 12 weeks of age were fed a standard or high fat diet with or without AVE7688 for 24 weeks. DIO rats had impaired glucose tolerance and developed sensory neuropathy. Vascular relaxation to acetylcholine and calcitonin gene-related peptide was decreased in epineurial arterioles of DIO rats. Rats fed a high fat diet containing AVE7688 did not become obese and vascular and sensory nerve dysfunction and impaired glucose tolerance were improved. DIO is associated with increased expression of NEP in epineurial arterioles. NEP degrades vasoactive peptides which may explain the decrease in neurovascular function in DIO.
\end{abstract}

\section{Introduction}

Previously, we demonstrated that high-fat fed rats, a model for diet-induced obesity, develop microvascular and neural deficits independent of hyperglycemia and this was accompanied by an increase in the expression of neutral endopeptidase in epineurial arterioles, vessels that provide circulation to the sciatic nerve [1]. In the present study, we sought to determine whether treatment of high-fat fed rats with AVE7688, a vasopeptidase inhibitor, for 24 weeks beginning at 12 weeks of age could improve microvascular dysfunction and prevent the slowing of sensory nerve conduction velocity. Vasopeptidase inhibitors are a new class of drugs that simultaneously inhibits neutral endopeptidase (NEP) and angiotensin converting enzyme (ACE) activity [2]. Recent studies have shown increased expression of angiotensin II-forming enzymes in adipose tissue, and increased activity of the renin-angiotensin system has been implicated in the development of insulin resistance and type 2 diabetes [3]. Neutral endopeptidase is found in many tissues including vascular and nerve tissue and its activity is increased by fatty acids and glucose in human microvascular cells [4-8]. Neutral endopeptidase degrades many vasoactive peptides including natriuretic peptides, adrenomedullin, bradykinin, and calcitonin gene-related peptide $[9,10]$. Therefore, inhibition of ACE and NEP activity would be expected to improve vascular function. In this regard, we have demonstrated that treating type 1 and type 2 diabetic rats as well as a genetic rat model of obesity with AVE7688 improves vascular and neural dysfunction [11-13]. However, no information is available about the effect of vasopeptidase inhibitors in an animal model of diet-induced obesity.

\section{Materials and Methods}

Unless stated otherwise, all chemicals used in these studies were obtained from Sigma Chemical Co. (St. Louis, MO).

2.1. Animals. Male Sprague-Dawley (Harlan Sprague Dawley, Indianapolis, IN) rats 10-11 weeks of age were housed in a certified animal care facility and food (Harlan Teklad, \#7001, Madison, WI) and water were provided ad libitum. All institutional (ACURF \#0691101), VAMC, and NIH guidelines for use of animals were followed. At 12 weeks of age the rats were weighed and randomly divided into six groups. One group was maintained on a normal diet. 
A second group was maintained on a normal diet containing $500 \mathrm{mg} / \mathrm{kg}$ AVE7688 (Ilepatril, Sanofi Aventis). Group 3 was placed on a high-fat diet. Group 4 was placed on a highfat diet containing $500 \mathrm{mg} / \mathrm{kg}$ AVE7688, which inhibits both ACE and NEP activity. In order to determine the role of ACE and NEP inhibition independently rats (Groups 5 and 6) were fed a high-fat diet containing Enalapril $(500 \mathrm{mg} / \mathrm{kg}$, ACE inhibitor) or Candoxatril (300 mg/kg, NEP inhibitor), respectively. The high-fat diet contained $24 \mathrm{gm} \%$ fat, $24 \mathrm{gm} \%$ protein, and $41 \mathrm{gm} \%$ carbohydrate (D12451; Research Diets, New Brunswick, NJ). The primary source of the increased fat content in the diet was soybean oil and lard. The average fat content of the control diet was $4.25 \mathrm{gm} \%$ (Harlan Teklad, \#7001, Madison, WI).

2.2. Glucose Tolerance. Glucose tolerance was determined by injecting rats with a saline solution containing $2 \mathrm{~g} / \mathrm{kg}$ glucose, i.p., after an overnight fast. Immediately prior to the glucose injection and for 240 minutes afterwards blood samples were taken to measure circulating glucose levels using glucose oxidase reagent strips (Lifescan Inc., Milpitas, CA). Fasting basal levels of insulin and leptin was also determined using Luminex technology.

2.3. Thermal Nociceptive Response. The day before terminal studies, thermal nociceptive response in the hindpaw was measured using the Hargreaves method as previously described [14].

2.4. Motor and Sensory Nerve Conduction Velocity and Biological and Oxidative Stress Markers. On the day of terminal studies, rats were weighed and anesthetized with Nembutal i.p. $(50 \mathrm{mg} / \mathrm{kg}$, i.p., Abbott Laboratories, North Chicago, IL). Serum samples were collected for determination of free fatty acid, triglyceride, free cholesterol, adiponectin, 8-hydroxy deoxyguanosine (8-OH DG), and angiotensin converting enzyme activity, using commercial kits from Roche Diagnostics, Mannheim, Germany; Sigma Chemical Co., St. Louis, MO; Bio Vision, Mountain View, CA; ALPCO diagnostics, Windham, NH, Cell Biolabs, Inc., San Diego, CA; ALPCO diagnostics, Windham, NH, respectively. Serum thiobarbituric acid reactive substances (TBARS) levels were also determined as an additional marker of oxidative stress as previously described [15].

Motor and sensory nerve conduction velocity was determined as previously described and afterwards the left gastrocnemius muscle, epididymal fat pad, interscalpel brown fat pad, and tissue containing the epineurial arterioles was collected [16-18]. The gastrocnemius muscle, epididymal fat pad and interscalpel brown fat pad were weighed.

\subsection{Intraepidermal Nerve Fiber Density in the Hindpaw.} Immunoreactive intraepidermal nerve fiber profiles were visualized using confocal microscopy. Samples of skin of the right hindpaw were fixed, dehydrated, and embedded in paraffin. Sections $(7 \mu \mathrm{m})$ were collected and immunostained with anti-PGP9.5 antibody (rabbit antihuman, AbD serotic, Morpho Sys US Inc., Raleigh, NC) over night followed by treatment with secondary antibody Alexa Fluor 546 goat antirabbit (Invitrogen, Eugene, OR). Profiles were counted by two individual investigators that were blinded to the sample identity. All immunoreactive profiles within the epidermis were counted and normalized to epidermal length $[1,19]$.

2.6. Vascular Reactivity. Videomicroscopy was used to investigate in vitro vasodilatory responsiveness of arterioles vascularizing the region of the sciatic nerve as previously described $[1,16,17]$. Cumulative concentration-response relationships were evaluated for acetylcholine $\left(10^{-8}-10^{-4} \mathrm{M}\right)$ and calcitonin gene-related peptide $\left(10^{-11}-10^{-8} \mathrm{M}\right)$ (CGRP) using vessels from each group of rats. At the end of the acetylcholine concentration response curve a maximal dose of sodium nitroprusside $\left(10^{-4} \mathrm{M}\right)$ was added in order to determine the endothelium-independent relaxation potential. At the end of each dose response curve for acetylcholine or CGRP papaverine $\left(10^{-5} \mathrm{M}\right)$ was added to determine maximal vasodilation.

2.7. Data Analysis. Results are presented as mean \pm SEM. Comparisons between the groups were conducted using one-way ANOVA and Bonferroni post-test (Prism software; GraphPad, San Diego, CA). Concentration response curves for acetylcholine and CGRP were compared using a two-way repeated measures analysis of variance with autoregressive covariance structure using proc mixed program of SAS [16, 17]. A $P$-value of less than .05 was considered significant.

\section{Results}

3.1. Effect of AVE7688 Treatment on Weight and Metabolic Parameters Induced by a High-Fat Diet. Sprague Dawley rats at 12 weeks of age were placed on a normal diet with or without $500 \mathrm{mg} / \mathrm{kg}$ AVE7688 or a high-fat diet ( $45 \% \mathrm{kcal}$ fat) with or without AVE7688, Enalapril, or Candoxatril for 24 weeks. During the course of the study the rats on the control diet ate $54 \mathrm{~g} / \mathrm{kg}$ rat/day and the rats on the high-fat diet or high-fat diet containing AVE7688, Enalapril, or Candoxatril ate $33,35,33$ or $32 \mathrm{~g} / \mathrm{day} / \mathrm{kg}$ rat, respectively. At the end of the study period rats on the high-fat diet weighed significantly more then rats on the control diet (Table 1). However, highfat fed rats treated with AVE7688 or Enalapril weighed significantly less than the high-fat fed rats. In contrast, highfat fed rats treated with Candoxatril weighed significantly more than the control or high-fat fed rats. All groups of rats weighed approximately the same at the beginning of the study and nonfasting blood glucose levels at the end of the study were similar for rats in all six groups. Adding AVE7688 to the control diet also reduced weight gain over 24 weeks but this difference was not significant compared to control. The weight of the left gastrocnemius muscle was not different for the 6 groups of rats. In contrast, weight of the epididymal fat pad was significantly increased in high-fat fed rats and highfat fed rats treated with Enalapril or Candoxatril compared to control. Weight of the epididymal fat pad was significantly less in rats fed a high-fat diet containing AVE7688 or 
TABLE 1: Effect of high-fat diet \pm AVE7688, Enalapril or Candoxatril on blood glucose and change in body weight, fat pad and muscle mass.

\begin{tabular}{|c|c|c|c|c|c|c|}
\hline Determination & $\begin{array}{l}\text { Control } \\
\text { (23) }\end{array}$ & $\begin{array}{c}\text { Control + } \\
\text { AVE7688 } \\
\quad(8)\end{array}$ & $\begin{array}{l}\text { High Fat } \\
(24)\end{array}$ & $\begin{array}{c}\text { High Fat + } \\
\text { AVE7688 } \\
(28)\end{array}$ & $\begin{array}{l}\text { High Fat + } \\
\text { Enalapril } \\
\quad(6)\end{array}$ & $\begin{array}{l}\text { High Fat }+ \\
\text { Candoxatril } \\
\text { (6) }\end{array}$ \\
\hline Start Body Weight (g) & $338 \pm 3$ & $327 \pm 5$ & $340 \pm 2$ & $336 \pm 3$ & $353 \pm 7$ & $354 \pm 4$ \\
\hline End Body Weight (g) & $485 \pm 7$ & $454 \pm 5$ & $560 \pm 9^{a}$ & $459 \pm 7^{\mathrm{b}}$ & $495 \pm 15^{b}$ & $643 \pm 20^{\mathrm{a}, \mathrm{b}}$ \\
\hline Blood glucose (mg/dL) & $93 \pm 6$ & $93 \pm 7$ & $96 \pm 6$ & $88 \pm 5$ & $111 \pm 6$ & $116 \pm 11$ \\
\hline Epididymal fat pad $(\mathrm{g})$ & $5.6 \pm 0.4$ & $4.2 \pm 0.2$ & $12.0 \pm 0.6^{\mathrm{a}}$ & $6.5 \pm 0.4^{\mathrm{b}}$ & $8.3 \pm 1.2^{\mathrm{a}, \mathrm{b}}$ & $17.3 \pm 1.6^{\mathrm{a}, \mathrm{b}}$ \\
\hline Interscapular Brown fat pad (g) & $0.38 \pm 0.02$ & $0.34 \pm 0.03$ & $0.68 \pm 0.04^{\mathrm{a}}$ & $0.44 \pm 0.01^{\mathrm{b}}$ & ND & ND \\
\hline Gastrocnemius muscle (g) & $3.3 \pm 0.1$ & $3.2 \pm 0.1$ & $3.4 \pm 0.1$ & $3.1 \pm 0.1$ & $3.1 \pm 0.1$ & $3.6 \pm 0.1$ \\
\hline
\end{tabular}

Data are presented as the mean \pm SEM. ${ }^{\mathrm{a}} P<.05$ compared to control; ${ }^{\mathrm{b}} P<.05$ compared to high-fat. ND equals not determined. Parentheses indicate the number of experimental animals in each group.

Enalapril, compared to high-fat fed rats.. The weight of the interscapular brown fat pad was significantly increased in high-fat fed rats compared to control and this was prevented when the rats on the high-fat diet were treated with AVE7688.

Serum was collected from rats fed the control, high-fat, and high-fat with AVE7688, Enalapril, or Candoxatril diets and used to measure a number of physiological parameters. Data in Table 2 demonstrate that fasting insulin and leptin levels are significantly increased in rats fed a high-fat diet and that this was prevented when the high-fat diet contained AVE7688. Feeding rats a high-fat diet containing Enalapril also significantly reduced serum insulin levels and leptin levels (but not significantly) compared to high-fat fed rats. Serum insulin and leptin levels were significantly increased in rats fed a high-fat diet containing Candoxatril compared to control. Data in Figure 1 show that glucose tolerance was impaired in high-fat fed rats compared to control rats and this was improved by adding AVE7688 to the high-fat diet. In contrast, adding Enalapril or Candoxatril to the high-fat diet did not improve glucose tolerance. Combined these data indicate that high-fat fed rats show signs of insulin resistant and this can be prevented by AVE7688.

Serum cholesterol levels are significantly increased in high-fat fed rats and this was prevented by AVE7688, Enalapril or Candoxatril (Table 2). Serum free fatty acids and triglycerides levels are elevated in high-fat fed rats and this was not prevented by adding AVE7688, Enalapril, or Candoxatril to the high-fat diet (Table 2). Serum markers for oxidative stress, 8-OH- deoxyguanosine and thiobarbituric acid reactive substances (TBARS) and adiponectin are significantly increased in rats fed a high-fat diet and this was prevented by adding AVE7688 to the high-fat diet (Table 2). Adding Enalapril or Candoxatril to the high-fat diet reduced 8-OH- deoxyguanosine levels but not TBARS levels. In contrast, adding Candoxatril to the high-fat diet reduced both $8-\mathrm{OH}$ - deoxyguanosine levels but not TBARS levels.

\subsection{Effect of a High-Fat Diet and AVE7688 Treatment on} Neural and Vascular Function. Data in Figure 2 demonstrate that sensory nerve conduction velocity was decreased in rats fed a high-fat diet and this was prevented by AVE7688 and

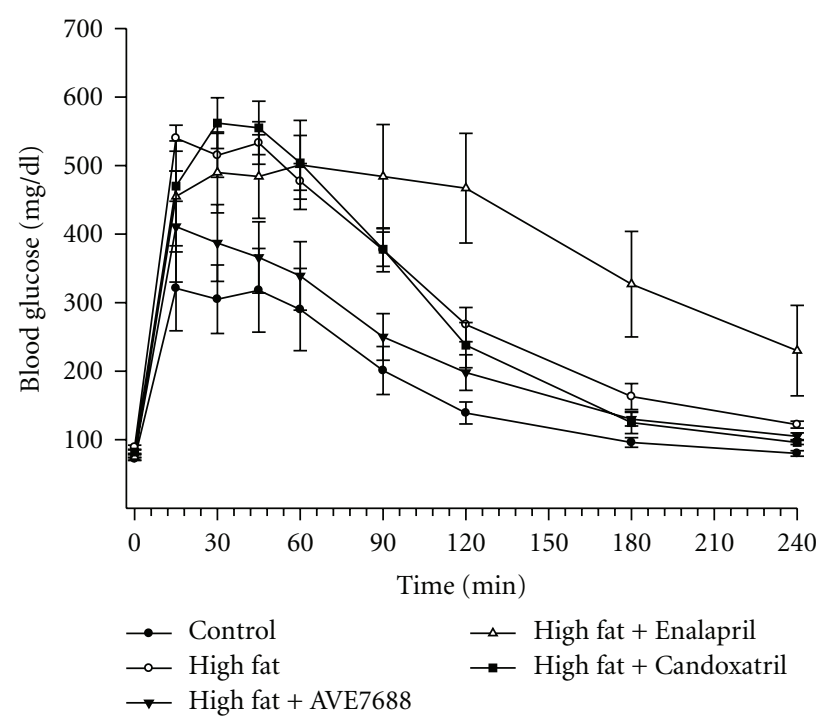

FIGURE 1: Effect of a high-fat diet and treatment with AVE7688 on glucose tolerance. Rats were fed a standard or high-fat diet with or without AVE7688, Enalapril, or Candoxatril for 24 weeks. Afterwards glucose tolerance was determined as described in Section. Data are presented as the mean \pm SEM in $\mathrm{mg} / \mathrm{dL}$. The area under the curve (AUC) was significantly different $P<.01$ for high-fat fed rats versus control. There was no significant difference for AUC between rats fed a high-fat diet containing AVE7688 and control or high-fat fed rats. Feeding rats a high-fat diet containing Enalapril or Candoxatril provided no improvement in impaired glucose tolerance caused by the high-fat diet. The number of rats in each group was the same as shown in Table 1.

Candoxatril treatment. Enalapril treatment of high-fat fed rats also improved sensory nerve conduction velocity but the difference between the high-fat fed group and Enalapril treated group was not significant. Motor nerve conduction velocity was not significantly affected by high-fat diet or treatments Data in Figure 3 demonstrate that rats fed a high-fat diet for 24 weeks become thermal hypoalgesic and that intraepidermal nerve fiber profiles in the hindpaw are decreased (Figure 3 ) and these significant changes are prevented by adding AVE7688 to the high-fat diet. Adding 
TABLE 2: Effect of high fat diet \pm AVE7688, Enalapril or Candoxatril on change in serum insulin, leptin, cholesterol, triglycerides, free fatty acids, adiponectin, 8-hydroxy deoxyguanosine, TBARS, and ACE activity.

\begin{tabular}{|c|c|c|c|c|c|}
\hline Determination & $\begin{array}{l}\text { Control } \\
\text { (23) }\end{array}$ & $\begin{array}{l}\text { High Fat } \\
\quad(24)\end{array}$ & $\begin{array}{c}\text { High Fat }+ \text { AVE7688 } \\
(28)\end{array}$ & $\begin{array}{c}\text { High Fat }+ \text { Enalapril } \\
(6)\end{array}$ & $\begin{array}{c}\text { High Fat }+ \text { Candoxatril } \\
(6)\end{array}$ \\
\hline Insulin (ng/mL) & $1.28 \pm .09$ & $3.60 \pm 0.43^{\mathrm{a}}$ & $1.78 \pm 0.17^{\mathrm{b}}$ & $0.67 \pm 0.05^{\mathrm{b}}$ & $3.74 \pm 1.19^{\mathrm{a}}$ \\
\hline Leptin (pM) & $446 \pm 81$ & $2052 \pm 389^{a}$ & $592 \pm 75^{\mathrm{b}}$ & $1442 \pm 430$ & $2852 \pm 260^{\mathrm{a}}$ \\
\hline Cholesterol (mg/dL) & $303 \pm 31$ & $680 \pm 29^{a}$ & $347 \pm 15^{b}$ & $201 \pm 22^{\mathrm{b}}$ & $255 \pm 49$ \\
\hline Triglycerides (mg/dL) & $41.8 \pm 4.1$ & $71.5 \pm 11.7$ & $72.0 \pm 9.1$ & $67.3 \pm 5.3$ & $72.2 \pm 8.9$ \\
\hline Free fatty acids (mmol/L) & $0.10 \pm 0.01$ & $0.20 \pm 0.03^{\mathrm{a}}$ & $0.21 \pm 0.02^{\mathrm{a}}$ & $0.28 \pm 0.04^{\mathrm{a}}$ & $0.20 \pm 0.04$ \\
\hline Adiponectin $(\mu \mathrm{g} / \mathrm{mL})$ & $7.9 \pm 0.6$ & $11.0 \pm 0.7^{\mathrm{a}}$ & $9.5 \pm 0.5$ & $7.7 \pm 0.7$ & $7.8 \pm 0.7$ \\
\hline 8-OH DG (ng/mL) & $1.88 \pm 0.10$ & $2.58 \pm 0.17^{\mathrm{a}}$ & $1.91 \pm 0.17^{\mathrm{b}}$ & $1.85 \pm 0.09$ & $1.88 \pm 0.14$ \\
\hline TBARS $(\mu \mathrm{g} / \mathrm{mL})$ & $0.13 \pm 0.01$ & $0.50 \pm 0.07^{\mathrm{a}}$ & $0.26 \pm 0.05^{\mathrm{b}}$ & $0.71 \pm 0.03^{\mathrm{a}}$ & $0.55 \pm 0.02^{\mathrm{a}}$ \\
\hline ACE activity (mU/mL/min) & $94 \pm 8$ & $75 \pm 6$ & $23 \pm 2^{\mathrm{a}, \mathrm{b}}$ & $4 \pm 1^{\mathrm{a}, \mathrm{b}}$ & $111 \pm 14$ \\
\hline
\end{tabular}

Data are presented as the mean \pm SEM. ${ }^{a} P<.05$ compared to control; ${ }^{b} P<.05$ compared to high-fat. ND equals not determined. Parentheses indicate the number of experimental animals in each group.

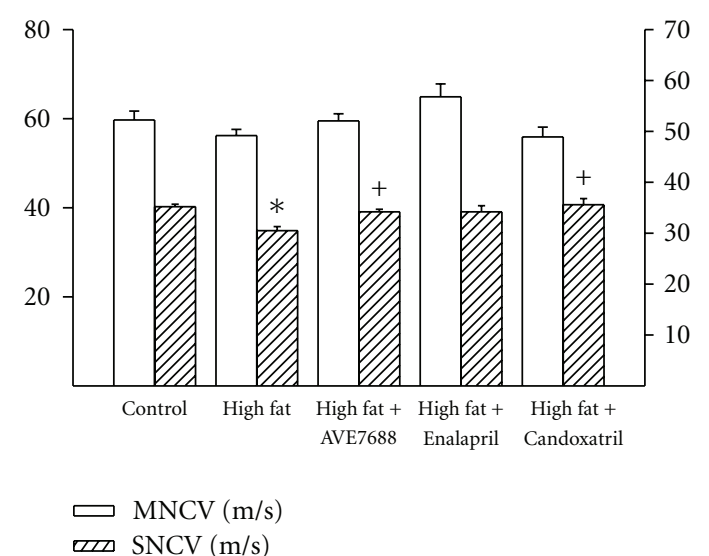

Figure 2: Effect of a high-fat diet and treatment with AVE7688 on motor and sensory nerve conduction velocity. Rats were fed a standard or high-fat diet with or without AVE7688, Enalapril or Candoxatril for 24 weeks. Data are presented as the mean \pm SEM for motor and sensory nerve conduction velocity in $\mathrm{m} / \mathrm{sec}$. The number of rats in each group was the same as shown in Table 1. ${ }^{*} P<.05$, compared to rats fed the standard diet (control), ${ }^{+} P<$ .05 , compared to rats fed the high-fat diet.

Candoxatril to the high-fat diet also prevented the impairment in thermal nociception and the significant decrease in intraepidermal nerve fiber profiles. Supplementing the highfat diet with Enalapril also improved thermal nociception compared to high-fat fed rats but to a lesser extent than AVE7688 or Candoxatril. In contrast, adding Enalapril to the high-fat diet did not improve the reduction in intraepidermal nerve fiber profiles compared to high-fat fed rats. Feeding control rats a standard diet containing AVE7688 did not affect motor and sensory nerve conduction velocity, thermal nociception or innervations, of the hindpaw (data not shown).

Vascular relaxation in response to acetylcholine and calcitonin gene-related peptide by epineurial arterioles from high-fat fed rats are significantly decreased compared to rats fed a control diet or a high-fat diet containing AVE7688

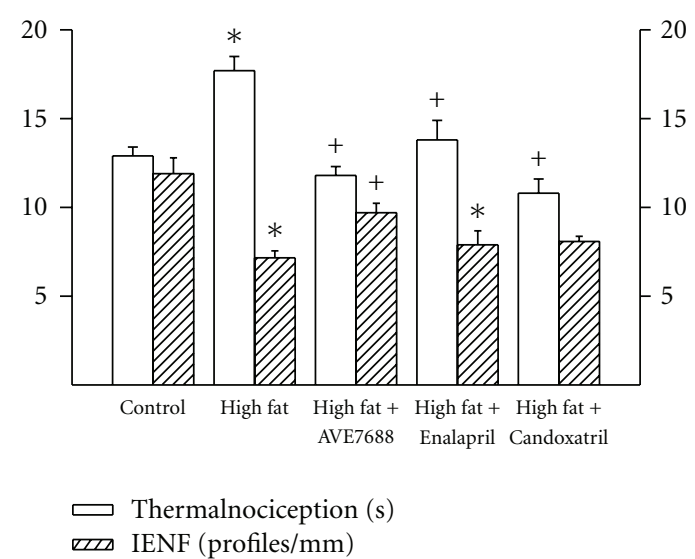

FIGURE 3: Effect of a high-fat diet and treatment with AVE7688 on thermal nociception and intraepidermal nerve fiber profiles in the hindpaw. Rats were fed a standard or high-fat diet with or without AVE7688, Enalapril or Candoxatril for 24 weeks. Data are presented as the mean \pm SEM for thermal nociception in sec and intraepidermal nerve fiber profiles per $\mathrm{mm}$. The number of rats in each group was the same as shown in Table $1 .{ }^{*} P<.05$, compared to rats fed the standard diet (control), ${ }^{+} P<.05$, compared to rats fed the high -fat diet.

(Figures 4 and 5, resp.). Treating rats with a high-fat diet containing Enalapril, or Candoxatril also improved vascular relaxation in response to acetylcholine and calcitonin generelated peptide with Candoxatril having a better efficacy than Enalapril. Feeding control rats a standard diet containing AVE7688 did not affect vascular reactivity activity in epineurial arterioles (data not shown).

\section{Discussion}

Previously, we have demonstrated that treatment of types 1 and 2 diabetic rats and nondiabetic obese Zucker rats with AVE7688, a vasopeptidase inhibitor, is effective in improving microvascular and neural complications [1113]. We have also reported that treatment of diabetic rats with AVE7688 may be more efficacious then monotherapy 


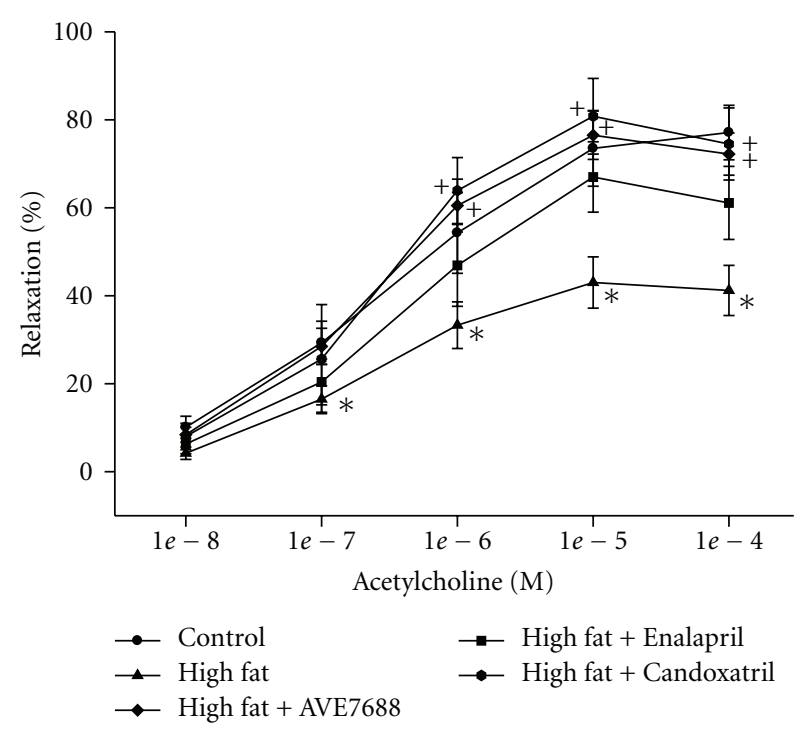

Figure 4: Effect of a high-fat diet and treatment with AVE7688 on acetylcholine-mediated vascular relaxation of epineurial arterioles. Rats were fed a standard or high-fat diet with or without AVE7688, Enalapril, or Candoxatril for 24 weeks. Pressurized arterioles (40 $\mathrm{mm} \mathrm{Hg}$ and ranging from $60-100 \mu \mathrm{m}$ luminal diameter) were constricted with U46619 (30\%-50\%) and incremental doses of acetylcholine were added to the bathing solution while recording steady state vessel diameter. Data are presented as the mean of \% relaxation \pm SEM. For these studies, two vessels were collected from each rat, studied, and the data combined. The number of rats in each group was the same as shown in Table $1 .{ }^{*} P<.05$, compared to rats fed the standard diet (control), ${ }^{+} P<.05$, compared to rats fed the high-fat diet.

using an angiotensin converting enzyme inhibitor [20]. Given these results, we were interested in determining the effect AVE7688 treatment would have on microvascular and neural complications in a rat model of diet-induced obesity [1]. The primary hypothesis to be examined was that treatment of rats fed a high-fat diet with AVE7688 will prevent vascular and neural dysfunction and that dual inhibition of angiotensin converting enzyme and neutral endopeptidase would be more effective than monotherapy. To test this hypothesis high-fat fed rats were treated with or without AVE7688, Enalapril, or Candoxatril. After 24 weeks a number of endpoints were examined to determine the effect of treatments on obesity related changes in weight, insulin resistance, oxidative stress, and vascular and neural function.

The characteristics of the diet induced obesity rat model are insulin resistance, impaired glucose intolerance, dyslipidemia and increased fat deposit but not hyperglycemia [21-26]. Studies have also demonstrated an increase in oxidative stress $[27,28]$. In a recent study, we found that rats fed a high-fat diet develop sensory neuropathy as indicated by slowing of sensory nerve conduction velocity, thermal hypoalgesia, and decrease in intraepidermal nerve fiber profiles. In contrast, endoneurial blood flow of the sciatic nerve and motor nerve conduction were not changed [1]. We also found that relaxation of epineurial arterioles to acetylcholine and CGRP was decreased in high-fat fed

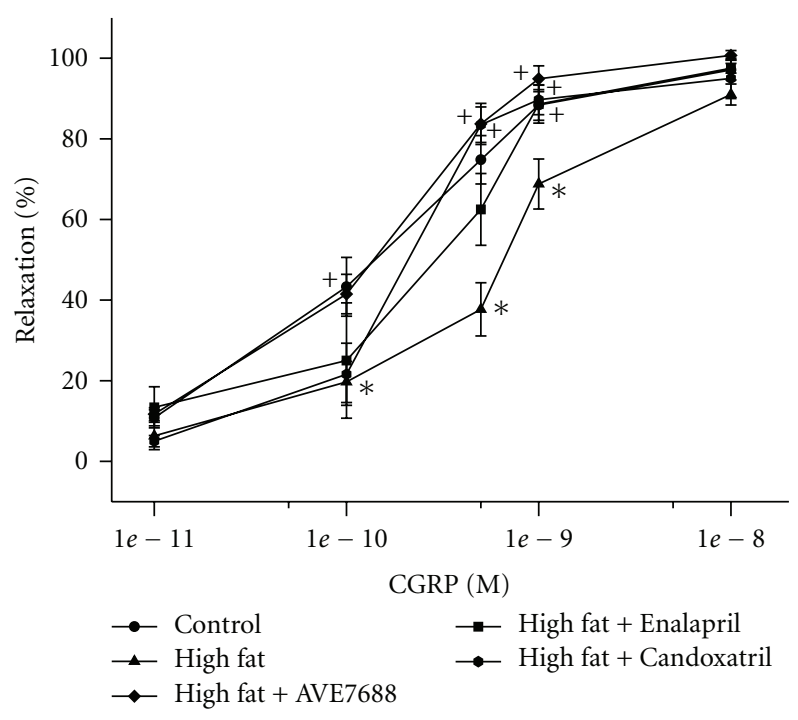

FIGURE 5: Effect of a high-fat diet and treatment with AVE7688 on calcitonin gene-related peptide-(CGRP)-mediated vascular relaxation of epineurial arterioles. Rats were fed a standard or highfat diet with or without AVE7688, Enalapril, or Candoxatril for 24 weeks. Arterioles were derived from rats as described in Figure 4. Incremental doses of CGRP were added to the bathing solution while recording steady state vessel diameter. Data are presented as the mean of $\%$ relaxation \pm SEM. The number of rats in each group was the same as shown in Table $1 .{ }^{*} P<.05$, compared to rats fed the standard diet (control), ${ }^{+} P<.05$, compared to rats fed the highfat diet.

rats, but unlike diabetic rats, oxidative stress in epineurial arterioles was not increased $[11,12,15,16]$. Moreover, we found that expression and activity of neutral endopeptidase in epineurial arterioles was increased in high-fat fed rats. This led us to speculate that treating high-fat fed rats with AVE7688 could be efficacious in improving vascular and neural defects associated with diet induced obesity. Since AVE7688 is an inhibitor of both angiotensin converting enzyme and neutral endopeptidase we also investigated the role of Enalapril, an inhibitor of angiotensin converting enzyme, and Candoxatril, an inhibitor of neutral endopeptidase, on weight gain and vascular and neural function in rats fed a high-fat diet.

The most important findings of this study was that rats fed a high-fat diet containing AVE7688 do not become obese and treatment prevented development of the vascular and neural dysfunction associated with diet induced obesity. Treatment of high-fat fed rats with AVE7688 over a period of 24 weeks using a prevention protocol prevented weight gain and mass of white and brown fat pads from high-fat fed rats treated with AVE7688 was significantly less compared to high-fat fed rats. Treating high-fat fed rats with Enalapril also reduced weight gain and the weight of the epididymal fat pad was significantly less compared to high-fat fed rats but was also significantly more than control rats. In contrast, treating high-fat fed rats with Candoxatril caused a greater weight gain and accumulation of epididymal fat pad mass compared to high-fat fed rats. Analysis of glucose tolerance revealed 
that treatment of high-fat fed rats with AVE7688 prevented impairment of glucose utilization in rats fed a high-fat diet. Glucose tolerance of high-fat fed rats treated with Enalapril or Candoxatril remained significantly impaired.

Previous studies have shown that diet induced obesity in rodent models can be prevented by angiotensin converting enzyme inhibitors and angiotensin II receptor blockers [2932]. In addition, diet induced weight gain and fat mass is reduced, energy expenditure increased, and glucose tolerance improved in mice lacking angiotensin converting enzyme or the angiotensin II type 1a receptor $[33,34]$. Therefore, we were surprised to find that glucose tolerance was not improved in high-fat fed rats treated with Enalapril. Studies showing improved insulin resistance with angiotensin converting enzyme inhibitor treatment of chronic diet-induced obesity have been done primarily with mice [30]. In rats de Kloet et al. [35] demonstrated that Captopril treatment of high-fat fed rats improved glucose tolerance. However, the duration of the high-fat diet in this study was 35 days. In comparison, the duration of high-fat diet in our study was 168 days. Other studies demonstrating improved glucose tolerance in rats treated with angiotensin converting enzyme inhibitor were performed using rat models of type 2 diabetes [36-38]. Therefore, the long term period of the high-fat diet in our study may explain why we failed to see an improvement in glucose tolerance in Enalapril treated highfat fed rats compared to the studies by de Kloet et al. [35].

Treating high-fat fed rats with Candoxatril provided no benefit toward reducing weight gain and fat mass or improving glucose tolerance. At the end of the study period, weight gain and epididymal fat pad mass were significantly higher in Candoxatril treated high-fat fed rats compared to high-fat fed rats. Therefore, inhibition of angiotensin converting enzyme or neutral endopeptidase alone is not sufficient to prevent obesity or insulin resistance in chronic high-fat fed rats.

The mechanisms proposed for the improvement in obesity and glucose tolerance with treatment of rodent models with angiotensin converting enzyme inhibitors are increased energy expenditure, liver and adipose tissue metabolic modulation, lower concentration of leptin, improved insulin signaling, and increased glucose and fatty acid utilization by muscle [29-34, 37-42]. In a study comparing the effects of Ramipril, an angiotensin converting enzyme inhibitor, to AVE7688 in JCR:LA-cp rats, an obese, insulin-resistant, hyperinsulinemic, normoglycemic model, it was found that both compounds reduced the surge of plasma insulin in a meal tolerance test by about 50\% but AVE7688 was more beneficial in improving vascular reactivity [43]. In another study using obese Zucker rats, it was found that dual inhibition of angiotensin converting enzyme and neutral endopeptidase improved insulin mediated glucose disposal more effectively than monotherapy and this effect was linked to increased activation of the kinin-nitric oxide pathway [44]. In a similar independent study, it was found that Omapatrilat, a vasopeptidase inhibitor, induced insulin sensitization and increased myocardial glucose uptake in obese Zucker rats and that the effect of Omapatrilat was greater than Ramipril in part due to stimulation of the $\mathrm{B}_{2}$ receptor [45]. Later this group reported that treatment of obese Zucker rats with a vasopeptidase inhibitor increased muscle glucose uptake independent of insulin signaling [46]. In two of these studies, protection of bradykinin from degradation by neutral endopeptidase was found to improve insulin action [44, 45]. Interestingly, it has been shown that natriuretic peptides promote muscle mitochondrial biogenesis and fat oxidation as to prevent obesity and glucose intolerance [47]. The natriuretic peptides are also degraded by neutral endopeptidase [20]. Because neutral endopeptidase is expressed in skeletal muscle in relatively large amounts and being located on the cell surface, neutral endopeptidase is able to hydrolyze peptides in the vicinity of their receptors thereby neutralizing their bioactivity [20, 48]. Since bradykinin and natriuretic peptides may have a role in regulating glucose and fatty acid metabolism by muscle protecting, their bioactive function by preventing degradation may be a therapeutic approach for treatment of obesity and insulin resistance [20,48].

The second major finding of this study was that treatment of diet-induced obese rats with AVE7688 prevented vascular and neural complications associated with obesity. Previously, we reported that treatment of types 1 and 2 diabetic rat models with AVE7688 improved vascular and neural complications and AVE7688 was more effective than angiotensin converting enzyme inhibition [1113, 20]. In these studies, treating high-fat fed rats with AVE7688 was generally more efficacious then Enalapril treatment in improving sensory neuropathy and vascular relaxation to acetylcholine and calcitonin gene-related peptide. We did not achieve significant differences between the AVE7688 and Enalapril treatment groups but we consistently found that treatment with AVE7688 and Candoxatril had better outcome for vascular and neural function than Enalapril.

It is well known that patients with impaired glucose tolerance are at increased risk for myocardial infarction, stroke, and large-vessel disease [49]. However, impaired glucose tolerance is also independently associated with traditional microvascular complications of diabetes including retinopathy, nephropathy, and polyneuropathy. Several mechanisms including inhibition of nitric oxide vasodilation, endothelial injury from hyperlipidemia and cytokines, and increased formation of reactive oxygen species have been cited as pathogenic causes for microvascular dysfunction associated with obesity and insulin resistance $[49,50]$. However, in our studies with high-fat fed rats and examination of the effect on vascular reactivity of epineurial arterioles, we have not been able to document an increase in reactive oxygen species in these vessels [1]. Thus, we cannot conclude that quenching of nitric oxide by superoxide is responsible for reducing acetylcholine-mediated vascular relaxation in epineurial arterioles. There is an increase in oxidative stress in high-fat fed rats as evidence by the increase of markers of oxidative stress in the serum that can be corrected by treatment with AVE7688 and to a lesser extent with Enalapril or Candoxatril. It is thought that a primary source of reactive oxygen species in the vasculature derived from obese models 
is $\mathrm{NAD}(\mathrm{P}) \mathrm{H}$ oxidase $[51,52]$. We have demonstrated that epineurial arterioles from diabetic rats generate reactive oxygen species and the primary source is the mitochondria [53]. We propose that in addition to increased oxidative stress other mechanisms may be responsible for microvascular dysfunction in obesity. One of these mechanisms is the increased expression/activity of neutral endopeptidase [20]. We have shown that diet-induced obesity causes an increase in the expression of neutral endopeptidase in epineurial arterioles [1]. In addition, it has been shown that hyperlipidemia and hyperglycemia increases neutral endopeptidase activity in human microvascular endothelial cells [6]. In these studies, we propose that AVE7688, Candoxatril, and to a lesser extent Enalapril may be protecting vascular reactivity and neural function by inhibiting neutral endopeptidase and the degradation of C-type natriuretic peptide and calcitonin gene-related peptide [11-13, 20].

\section{Conclusion}

Feeding rats a high-fat diet causes weight gain, impaired glucose tolerance, increased markers of oxidative stress, and vascular and sensory nerve dysfunction. Each of these obesity-induced pathogenic conditions was prevented by treating the high-fat fed rats with AVE7688 and treatment with AVE7688 was generally more effective than treatments with Enalapril or Candoxatril. Thus, we conclude that dual inhibition of angiotensin converting enzyme and neutral endopeptidase may be more effective than monotherapy in reducing insulin resistance and the complications associated with diet induced obesity.

\section{Acknowledgments}

This material is based upon work supported in part by the Department of Veterans Affairs, Veterans Health Administration, Office of Research and Development, Biomedical Laboratory Research and Development, by National Institute of Diabetes and Digestive and Kidney Diseases Grants DK073990 from NIH and by a research grant from the Juvenile Diabetes Research Foundation. The content of this manuscript are new and solely the responsibility of the authors and do not necessarily represent the official views of the granting agencies. The authors have no conflicts of interest to report. The authors would like to extend their appreciation to Sanofi Aventis, MERCK and Pfizer for supplying AVE7688 (Ilepatril), Enalapril and Candoxatril, respectively, for these studies.

\section{References}

[1] E. P. Davidson, L. J. Coppey, N. A. Calcutt, C. L. Oltman, and M. A. Yorek, "Diet-induced obesity in SpragueDawley rats causes microvascular and neural dysfunction," Diabetes/Metabolism Research and Reviews, vol. 26, no. 4, pp. 306-318, 2010.

[2] M. Weber, "Emerging treatments for hypertension: potential role for vasopeptidase inhibition," American Journal of Hypertension, vol. 12, no. 11, pp. 139S-147S, 1999.
[3] A. M. Sharma, "Is there a rationale for angiotensin blockade in the management of obesity hypertension?" Hypertension, vol. 44, no. 1, pp. 12-19, 2004.

[4] F. Ebihara, G. S. Di Marco, M. A. Juliano, and D. E. Casarini, "Neutral endopeptidase expression in mesangial cells," Journal of the Renin-Angiotensin-Aldosterone System, vol. 4, no. 4, pp. 228-233, 2003.

[5] H. Vatter, L. Schilling, P. Schmiedek, and H. Ehrenreich, "Evidence for functional endothelin-converting enzyme activity in isolated rat basilar artery: effect of inhibitors," Journal of Cardiovascular Pharmacology, vol. 31, no. 1, pp. S64-S67, 1998.

[6] P. Muangman, M. L. Spenny, R. N. Tamura, and N. S. Gibran, "Fatty acids and glucose increase neutral endopeptidase activity in human microvascular endothelial cells," Shock, vol. 19, no. 6, pp. 508-512, 2003.

[7] R. M. Edwards, M. Pullen, and P. Nambi, "Distribution of neutral endopeptidase activity along the rat and rabbit nephron," Pharmacology, vol. 59, no. 1, pp. 45-50, 1999.

[8] W. Gonzalez, J.-M. Soleilhac, M.-C. Fournié-Zaluski, B. P. Roques, and J.-B. Michel, "Characterization of neutral endopeptidase in vascular cells, modulation of vasoactive peptide levels," European Journal of Pharmacology, vol. 345, no. 3, pp. 323-331, 1998.

[9] Q. Pu and E. L. Schiffrin, "Effect of ACE/NEP inhibition on cardiac and vascular collagen in stroke-prone spontaneously hypertensive rats," American Journal of Hypertension, vol. 14, no. 10, pp. 1067-1072, 2001.

[10] J. S. Floras, "Vasopeptidase inhibition: a novel approach to cardiovascular therapy," Canadian Journal of Cardiology, vol. 18, no. 2, pp. 177-182, 2001.

[11] E. P. Davidson, T. L. Kleinschmidt, C. L. Oltman, D. D. Lund, and M. A. Yorek, "Treatment of streptozotocin-induced diabetic rats with AVE7688, a vasopeptidase inhibitor: effect on vascular and neural disease," Diabetes, vol. 56, no. 2, pp. 355-362, 2007.

[12] C. L. Oltman, E. P. Davidson, L. J. Coppey, T. L. Kleinschmidt, D. D. Lund, and M. A. Yorek, "Treatment of Zucker diabetic fatty rats with AVE7688 improves vascular and neural dysfunction," Diabetes, Obesity and Metabolism, vol. 11, no. 3, pp. 223-233, 2009.

[13] E. P. Davidson, L. J. Coppey, T. L. Kleinschmidt, C. L. Oltman, and M. A. Yorek, "Vascular and neural dysfunctions in obese Zucker rats: effect of AVE7688," Experimental Diabetes Research, vol. 2009, Article ID 912327, 8 pages, 2009.

[14] C. L. Oltman, E. P. Davidson, L. J. Coppey, T. L. Kleinschmidt, D. D. Lund, and M. A. Yorek, "Attenuation of vascular/neural dysfunction in zucker rats treated with enalapril or rosuvastatin," Obesity, vol. 16, no. 1, pp. 82-89, 2008.

[15] C. L. Oltman, L. J. Coppey, J. S. Gellett, E. P. Davidson, D. D. Lund, and M. A. Yorek, "Progression of vascular and neural dysfunction in sciatic nerves of Zucker diabetic fatty (ZDF) and Zucker rats," American Journal of Physiology, vol. 289, no. 1, pp. E113-E122, 2005.

[16] L. J. Coppey, J. S. Gellett, E. P. Davidson, J. A. Dunlap, D. D. Lund, and M. A. Yorek, "Effect of antioxidant treatment of streptozotocin-induced diabetic rats on endoneurial blood flow, motor nerve conduction velocity, and vascular reactivity of epineurial arterioles of the sciatic nerve," Diabetes, vol. 50, no. 8, pp. 1927-1937, 2001.

[17] L. J. Coppey, E. P. Davidson, T. W. Rinehart et al., "ACE inhibitor or angiotensin II receptor antagonist attenuates diabetic neuropathy in streptozotocin-induced diabetic rats," Diabetes, vol. 55, no. 2, pp. 341-348, 2006. 
[18] I. G. Obrosova, F. Li, O. I. Abatan et al., "Role of poly(ADPribose) polymerase activation in diabetic neuropathy," Diabetes, vol. 53, no. 3, pp. 711-720, 2004.

[19] K. K. Beiswenger, N. A. Calcutt, and A. P. Mizisin, "Epidermal nerve fiber quantification in the assessment of diabetic neuropathy," Acta Histochemica, vol. 110, no. 5, pp. 351-362, 2008.

[20] M. A. Yorek, "The potential role of angiotensin converting enzyme and vasopeptidase inhibitors in the treatment of diabetic neuropathy," Current Drug Targets, vol. 9, no. 1, pp. 77-84, 2008.

[21] L. Sedová, J. Bérubé, D. Gaudet et al., "Diet-induced obesity delays cardiovascular recovery from stress in spontaneously hypertensive rats," Obesity Research, vol. 12, no. 12, pp. 19511958, 2004.

[22] M. G. Dube, E. Beretta, H. Dhillon, N. Ueno, P. S. Kalra, and S. P. Kalra, "Central leptin gene therapy blocks high-fat dietinduced weight gain, hyperleptinemia, and hyperinsulinemia: increase in serum ghrelin levels," Diabetes, vol. 51, no. 6, pp. 1729-1736, 2002.

[23] F. Törüner, E. Akbay, N. Çakir et al., "Effects of PPAR $\gamma$ and PPAR $\alpha$ agonists on serum leptin levels in diet-induced obese rats," Hormone and Metabolic Research, vol. 36, no. 4, pp. 226230, 2004

[24] S. S. Gholami, R. Rogers, J. Chang et al., "The effect of vascular endothelial growth factor and adeno-associated virus mediated brain derived neurotrophic factor on neurogenic and vasculogenic erectile dysfunction induced by hyperlipidemia," Journal of Urology, vol. 169, no. 4, pp. 1577-1581, 2003.

[25] M. Tschöp and M. L. Heiman, "Rodent obesity models: an overview," Experimental and Clinical Endocrinology and Diabetes, vol. 109, no. 6, pp. 307-319, 2001.

[26] D. B. West and B. York, "Dietary fat, genetic predisposition, and obesity: lessons from animal models," American Journal of Clinical Nutrition, vol. 67, no. 3, pp. 505S-512S, 1998.

[27] A. D. Dobrian, M. J. Davies, S. D. Schriver, T. J. Lauterio, and R. L. Prewitt, "Oxidative stress in a rat model of obesity-induced hypertension," Hypertension, vol. 37, no. 2, pp. 554-560, 2001.

[28] C. M. Boustany, K. Bharadwaj, A. Daugherty, D. R. Brown, D. C. Randall, and L. A. Cassis, "Activation of the systemic and adipose renin-angiotensin system in rats with diet-induced obesity and hypertension," American Journal of Physiology, vol. 287, no. 4, pp. R943-R949, 2004.

[29] E. L. Santos, K. de Picoli Souza, P. B. Guimarães et al., "Effect of angiotensin converting enzyme inhibitor enalapril on body weight and composition in young rats," International Immunopharmacology, vol. 8, no. 2, pp. 247-253, 2008.

[30] R. S. Weisinger, T. K. Stanley, D. P. Begg, H. S. Weisinger, K. J. Spark, and M. Jois, "Angiotensin converting enzyme inhibition lowers body weight and improves glucose tolerance in C57BL/6J mice maintained on a high fat diet," Physiology and Behavior, vol. 98, no. 1-2, pp. 192-197, 2009.

[31] E. L. Santos, K. de Picoli Souza, E. D. da Silva et al., "Long term treatment with ACE inhibitor enalapril decreases body weight gain and increases life span in rats," Biochemical Pharmacology, vol. 78, no. 8, pp. 951-958, 2009.

[32] K. Araki, T. Masaki, I. Katsuragi, K. Tanaka, T. Kakuma, and H. Yoshimatsu, "Telmisartan prevents obesity and increases the expression of uncoupling protein 1 in diet-induced obese mice," Hypertension, vol. 48, no. 1, pp. 51-57, 2006.

[33] A. P. Jayasooriya, M. L. Mathai, L. L. Walker et al., "Mice lacking angiotensin-converting enzyme have increased energy expenditure, with reduced fat mass and improved glucose clearance," Proceedings of the National Academy of Sciences of the United States of America, vol. 105, no. 18, pp. 6531-6536, 2008.

[34] R. Kouyama, T. Suganami, J. Nishida et al., "Attenuation of diet-induced weight gain and adiposity through increased energy expenditure in mice lacking angiotensin II type 1a receptor," Endocrinology, vol. 146, no. 8, pp. 3481-3489, 2005.

[35] A. D. de Kloet, E. G. Krause, D.-H. Kim, R. R. Sakai, R. J. Seeley, and S. C. Woods, "The effect of angiotensin-converting enzyme inhibition using captopril on energy balance and glucose homeostasis," Endocrinology, vol. 150, no. 9, pp. 41144123, 2009.

[36] N. Harada, E. Takishita, N. Ishimura, A. Minami, S. Sakamoto, and Y. Nakaya, "Combined effect of ACE inhibitor and exercise training on insulin resistance in type 2 diabetic rats," Life Sciences, vol. 70, no. 15, pp. 1811-1820, 2002.

[37] M. Nawano, M. Anai, M. Funaki et al., "Imidapril, an angiotensin-converting enzyme inhibitor, improves insulin sensitivity by enhancing signal transduction via insulin receptor substrate proteins and improving vascular resistance in the Zucker fatty rat," Metabolism, vol. 48, no. 10, pp. 1248-1255, 1999.

[38] D. B. Dal Ponte, D. L. Fogt, S. Jacob, and E. J. Henriksen, "Interactions of captopril and verapamil on glucose tolerance and insulin action in an animal model of insulin resistance," Metabolism, vol. 47, no. 8, pp. 982-987, 1998.

[39] I. Tabbi-Anneni, J. Buchanan, R. C. Cooksey, et al., "Captopril normalizes insulin signaling and insulin-regulated substrate metabolism in obese (ob/ob) mouse hearts," Endocrinology, vol. 149, no. 8, pp. 4043-4050, 2008.

[40] E. J. Henriksen, S. Jacob, H. J. Augustin, and G. J. Dietze, “Glucose transport activity in insulin-resistant rat muscle: effects of angiotensin-converting enzyme inhibitors and bradykinin antagonism," Diabetes, vol. 45, no. 1, pp. S125-S128, 1996.

[41] E. J. Henriksen and S. Jacob, "Effects of captopril on glucose transport activity in skeletal muscle of obese Zucker rats," Metabolism, vol. 44, no. 2, pp. 267-272, 1995.

[42] K. Sugimoto, L. Kazdová, N. R. Qi et al., “Telmisartan increases fatty acid oxidation in skeletal muscle through a peroxisome proliferator-activated receptor- $\gamma$ dependent pathway," Journal of Hypertension, vol. 26, no. 6, pp. 1209-1215, 2008.

[43] J. C. Russell, S. E. Kelly, and S. Schäfer, "Vasopeptidase inhibition improves insulin sensitivity and endothelial function in the JCR:LA-cp rat," Journal of Cardiovascular Pharmacology, vol. 44, no. 2, pp. 258-265, 2004.

[44] V. Arbin, N. Claperon, M.-C. Fournié-Zaluski, B. P. Roques, and J. Peyroux, "Acute effect of the dual angiotensinconverting enzyme and neutral endopeptidase 24-11 inhibitor mixanpril on insulin sensitivity in obese Zucker rat," British Journal of Pharmacology, vol. 133, no. 4, pp. 495-502, 2001.

[45] C.-H. Wang, N. Leung, N. Lapointe et al., "Vasopeptidase inhibitor omapatrilat induces profound insulin sensitization and increases myocardial glucose uptake in Zucker fatty rats," Circulation, vol. 107, no. 14, pp. 1923-1929, 2003.

[46] V. Wong, L. Szeto, K. Uffelman, I. G. Fantus, and G. F. Lewis, "Enhancement of muscle glucose uptake by the vasopeptidase inhibitor, omapatrilat, is independent of insulin signaling and the AMP kinase pathway," Journal of Endocrinology, vol. 190, no. 2, pp. 441-450, 2006.

[47] K. Miyashita, H. Itoh, H. Tsujimoto et al., "Natriuretic peptides/cGMP/cGMP-dependent protein kinase cascades promote muscle mitochondrial biogenesis and prevent obesity," Diabetes, vol. 58, no. 12, pp. 2880-2892, 2009. 
[48] A. Broccolini, T. Gidaro, R. Morosetti et al., "Neprilysin participates in skeletal muscle regeneration and is accumulated in abnormal muscle fibres of inclusion body myositis," Journal of Neurochemistry, vol. 96, no. 3, pp. 777-789, 2006.

[49] J. R. Singleton, A. G. Smith, J. W. Russell, and E. L. Feldman, "Microvascular complications of impaired glucose tolerance," Diabetes, vol. 52, no. 12, pp. 2867-2873, 2003.

[50] D. W. Busija, A. W. Miller, P. Katakam, and B. Erdos, "Adverse effects of reactive oxygen species on vascular reactivity in insulin resistance," Antioxidants and Redox Signaling, vol. 8, no. 7-8, pp. 1131-1140, 2006.

[51] T. Inoguchi and $\mathrm{H}$. Nawata, "NAD $(\mathrm{P}) \mathrm{H}$ oxidase activation: a potential target mechanism for diabetic vascular complications, progressive $\beta$-cell dysfunction and metabolic syndrome," Current Drug Targets, vol. 6, no. 4, pp. 495-501, 2005.

[52] C. Rask-Madsen and G. L. King, "Mechanisms of disease: endothelial dysfunction in insulin resistance and diabetes," Nature Clinical Practice Endocrinology and Metabolism, vol. 3, no. 1, pp. 46-56, 2007.

[53] L. J. Coppey, J. S. Gellett, E. P. Davidson, and M. A. Yorek, "Preventing superoxide formation in epineurial arterioles of the sciatic nerve from diabetic rats restores endotheliumdependent vasodilation," Free Radical Research, vol. 37, no. 1, pp. 33-40, 2003. 


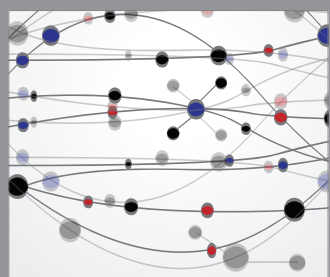

The Scientific World Journal
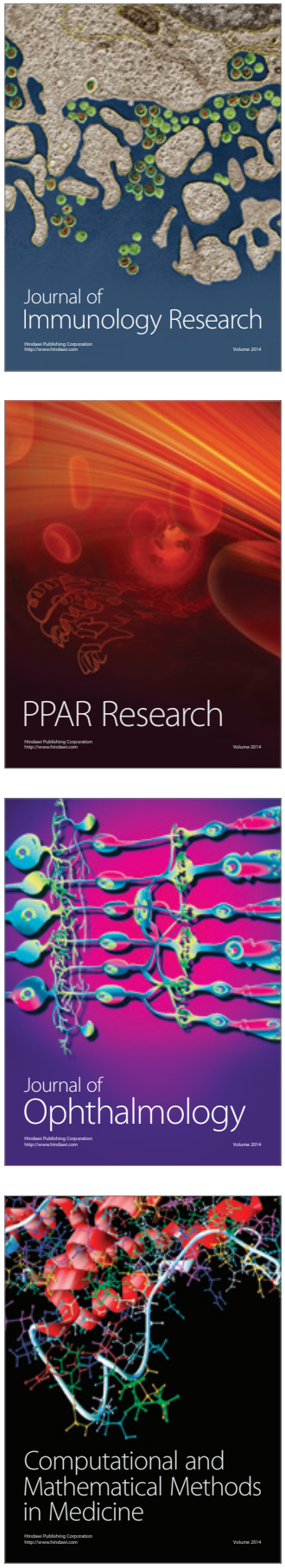

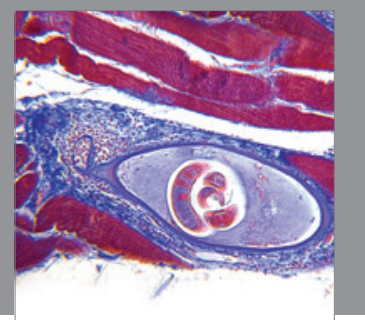

Gastroenterology

Research and Practice
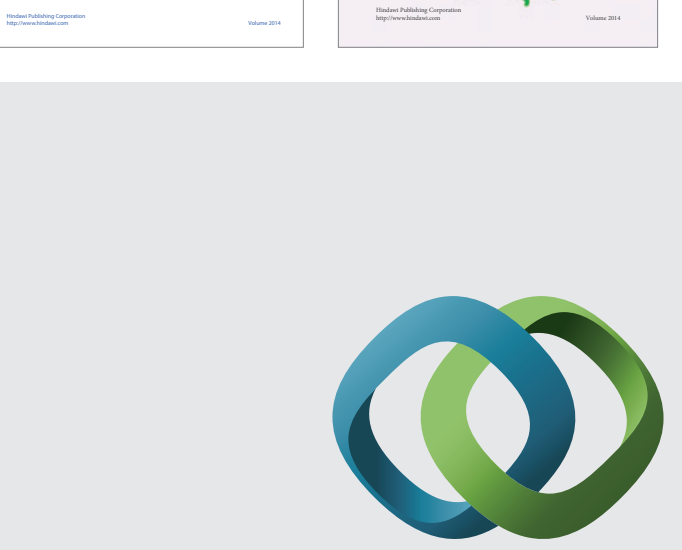

\section{Hindawi}

Submit your manuscripts at

http://www.hindawi.com
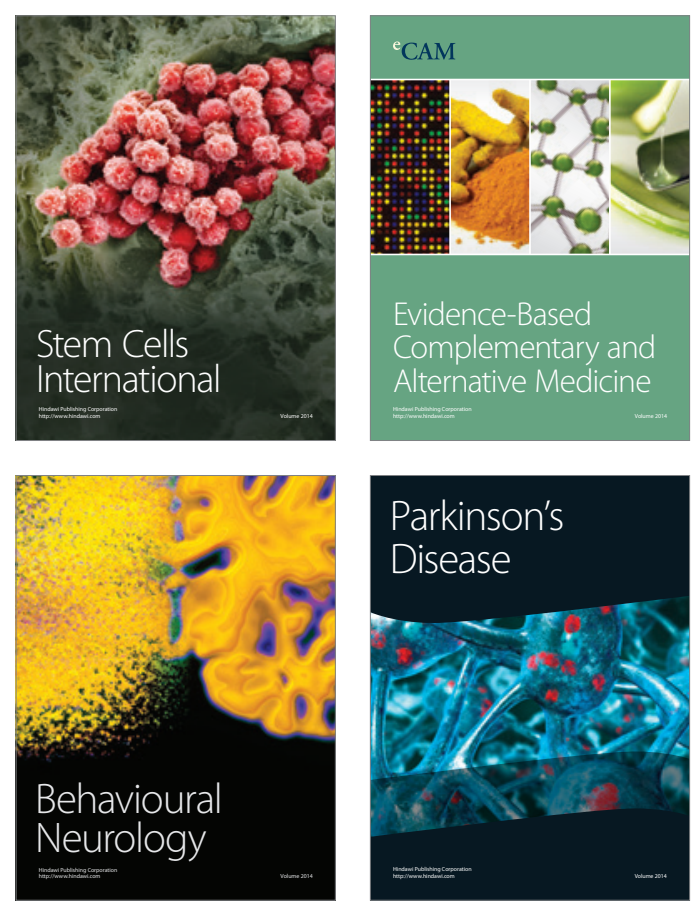

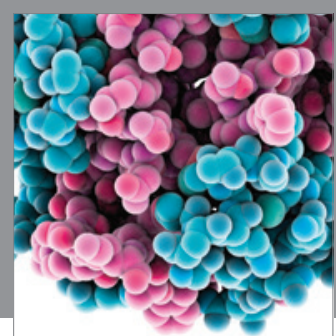

Journal of
Diabetes Research

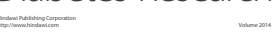

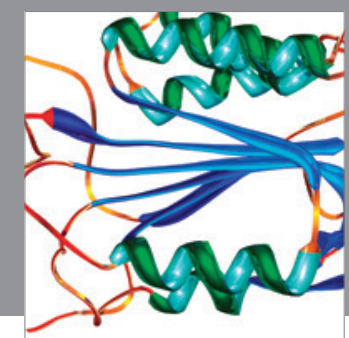

Disease Markers
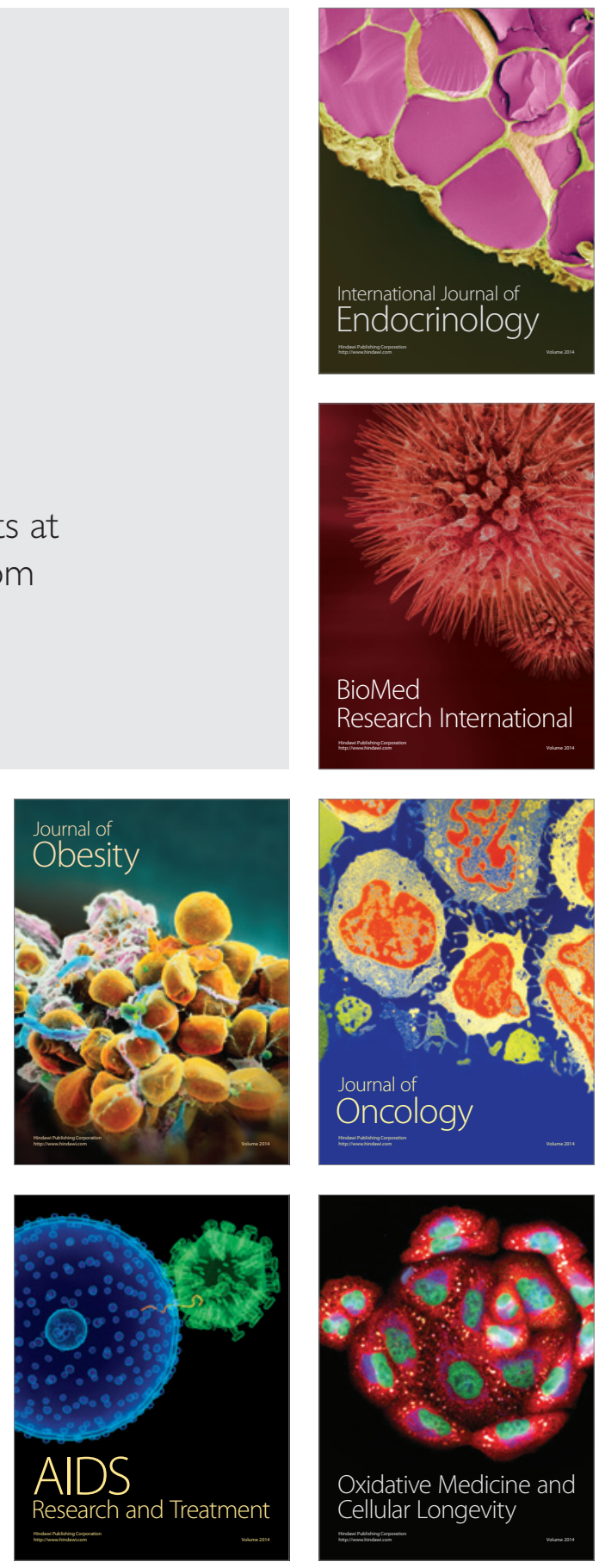